\title{
CONCEPÇÕES DE CUIDADO: UMA ANÁLISE DAS TESES APRESENTADAS PARA UM PROGRAMA DE PÓS-GRADUAÇÃO EM ENFERMAGEM ${ }^{1}$ CARE CONCEPTIONS: AN ANALYSIS OF Ph.D. DISSERTATIONS PRESENTED IN A NURSING GRADUATE PROGRAM CONCEPCIONES DEL CUIDADO: UN ANÁLISIS DE LAS TESIS PRESENTADAS A UN PROGRAMA DE POSTGRADO EN ENFERMERÍA
}

\author{
Dirce Stein Backes², Francisca Georgina Macêdo de Sousa ${ }^{3}$, Ana Lúcia Schaefer Ferreira de Mello ${ }^{4}$, Alacoque Lorenzini \\ Erdmann ${ }^{5}$, Keyla Cristiane Nascimento ${ }^{6}$, Juliana Cristina Lessmann ${ }^{7}$
}

${ }^{1}$ Trabalho apresentado no $3^{\circ}$ Seminário Internacional de Filosofia e Saúde, Florianópolis, outubro de 2006.

${ }^{2}$ Enfermeira. Doutoranda do Programa de Pós-Graduação (PEN) da Universidade Federal de Santa Catarina (UFSC). Membro do Grupo de Estudos e Pesquisas em Administração de Enfermagem e Saúde (GEPADES). Bolsista do Conselho Nacional de Desenvolvimento Científico e Tecnológico (CNPq). Santa Catarina, Brasil.

${ }^{3}$ Enfermeira. Docente do Curso de Enfermagem da Universidade Federal do Maranhão (UFMA). Doutoranda do PEN/UFSC. Membro do GEPADES. Bolsista do CNPq. Maranhão, Brasil.

${ }^{4}$ Odontóloga. Doutora em Enfermagem pelo PEN/UFSC. Membro do GEPADES. Santa Catarina, Brasil.

${ }^{5}$ Enfermeira. Doutora em Filosofia da Enfermagem. Professora Titular da UFSC. Pesquisadora do CNPq. Coordenadora do GEPADES. Santa Catarina, Brasil.

${ }^{6}$ Enfermeira. Doutoranda do PEN/UFSC. Membro do GEPADES. Santa Catarina, Brasil.

${ }^{7}$ Enfermeira. Membro do GEPADES. Santa Catarina, Brasil.

PALAVRAS-CHAVE: Enfermagem. Pesquisa em enfermagem. Educação de pósgraduação em enfermagem.
RESUMO: O cuidado, nas suas diferentes dimensões e interfaces, tem sido objeto de estudo de profissionais de saúde, os quais apontam experiências e resultados que tem influenciado a prática em saúde e na enfermagem. É crescente a produção científica no sentido de resgatar e tornar visível os movimentos dinâmicos do cuidado. Sob esta perspectiva definiu-se como objetivo do estudo analisar as concepções de cuidado expressas nas teses de doutoramento de um programa de pós-graduação em enfermagem. A investigação caracterizou-se como bibliográfica, de natureza qualitativa, tendo como universo 34 teses, de um total de 111 defendidas no período de 1995 a dezembro de 2005. São várias as concepções de cuidado onde cada autor coloca, além de sua visão de mundo, um referencial de vida e de prática profissional.
KEYWORDS: Nursing. Nursing research. Graduate nursing education.
ABSTRACT: Care, in its different dimensions and interfaces, has been an object of study for health care professionals, in which experiences and results have been influencing health care and nursing practices. Scientific production is increasing in the sense of rescuing and making the dynamic movements of care more visible. Under this perspective, the aim of this study was defined to analyze the care conceptions expressed in the doctorate dissertations of a nursing graduate program. The investigation was characterized as bibliographical of a qualitative nature. A universe of 34 theses, totaling 111 presented from the year 1995 to 2005, was used as an investigative sample. The appraised theses approach the inclusion and interactivity of the care and how much is internalized in doing and thinking on a daily basis in Nursing and society. Each author introduces his/her world vision, his/her life referential, and his/her professional practice in the elaboration of their conceptions and care.
PALABRAS CLAVE: Enfermería. Investigación en enfermería. Educación de postgrado en enfermería.
RESUMEN: En sus diferentes dimensiones e interfaces, el cuidado ha sido objeto de estudio de los profesionales de la salud, los cuales señalan las experiencias y resultados que han estado influyendo en la práctica de salud y en la enfermería. La producción científica es creciente en el sentido de rescatar y dejar visible los movimientos dinámicos del cuidado. Desde esta perspectiva, se definió como objetivo de este estudio analizar las concepciones del cuidado expresadas en las tesis presentadas a un programa de postgrado en enfermería. La investigación se caracterizó como siendo bibliográfica, de naturaleza cualitativa. Para el estudio fue considerado un universo de 34 tesis, de un total de 111 presentadas en el periodo de 1995 a 2005. En las tesis analizadas, son varias las concepciones del cuidado, donde cada autor introduce su visión de mundo, su referencial de vida y su práctica profesional en la elaboración de sus concepciones y cuidado.
Endereço: Dirce Stein Backes

R. Antenor Mesquita, 145, Ap. 903B

88.015-150 - Centro, Florianópolis, SC, Brasil.

E-mail: backesdirce@ig.com.br
Artigo original: Pesquisa

Recebido em: 28/10/2006

Aprovação final: 09/04/2007 


\section{INTRODUÇÃO}

Cuidar, receber cuidado, produzir cuidado, ou simplesmente manifestar cuidado. Eis as múltiplas expressões e compreensões que abarca a simples e, ao mesmo tempo, complexa, terminologia cuidado no processo de viver e produzir saúde. Simples, pela sua natureza, mas complexa pela sua singularidade, dinamicidade e interatividade que estabelece na existência humana, na sociedade em geral e particularmente no sistema de cuidados. ${ }^{1}$ Para qualquer alusão a respeito da compreensão de cuidado faz-se necessário um breve retorno ao passado, isto é, para o decurso da história do homem no que tange à perpetuação da espécie. A história da civilização humana demonstra que o cuidar sempre esteve presente nas diferentes dimensões do processo de viver, adoecer e morrer, mesmo antes do surgimento das profissões. ${ }^{2} \mathrm{O}$ cuidado orienta a condição essencial do ser humano e determina a estrutura da prática e o modo de ser e agir nos sistemas sociais e de cuidados em saúde.

De outro modo, o cuidado não se esgota na prática e nem mesmo na pesquisa, por isso é sempre novo e velho ao mesmo tempo. O cuidado, nas mais diferentes dimensões e variações históricas emerge, continuamente, como força propulsora e dinamizadora principalmente das ações de enfermagem. $\mathrm{O}$ profissional de enfermagem, mesmo que não lhe deva ser atribuído à exclusividade pelo cuidado, é quem empreende a maior parte do seu tempo, da sua energia, da sua vida para estar com o outro numa relação de reciprocidade e interatividade. Assim, o cuidado para a enfermagem "é oferecer ao outro, como forma de serviço, o resultado de nossos talentos, preparos e escolhas", $3: 76$ é ultrapassar a dimensão unicamente racional e assistencialista do fazer para alcançar a dimensão relacional e multidimensional do cuidado.

Essa forma singular de interação que o cuidado pressupõe e estabelece não pode ser alcançada, todavia, com uma formação que se limita aos procedimentos técnicos e/ou baseada numa simples intervenção profissional. ${ }^{2} \mathrm{O}$ ser humano, enquanto ser relacional e de múltiplas interações é dotado de atitudes de cuidado, seja na dimensão física, psíquica, social e/ou espiritual. Num sentido mais amplo e complexo, o cuidado faz parte da existência humana como manifestação de compartilhamento, de troca e de reciprocidade. Enquanto movimento dinâmico e processual, o cuidado vem sendo estudado e tem influenciado a teoria, a pesquisa, a prática e a educação em enfermagem, nas suas mais variadas formas e expressões definidas como assistir, ajudar e servir.
Nessa perspectiva, várias questões emergem e convergem para a necessidade de aprofundar e ampliar as concepções de cuidado na enfermagem e na saúde, dentre elas: o que significa o cuidado humanizado/ético/solidário? O que se entende por ambiente de cuidado? $\mathrm{O}$ que significa cuidado complexo em saúde? O que se compreende por cuidado enquanto produto de múltiplas interações humanas? O que representa o cuidado integral/interdisciplinar/multidimensional?

Para atender a amplitude destas questões ousamos, enquanto integrantes do Grupo de Estudos e Pesquisa em Administração de Enfermagem e Saúde (GEPADES), realizar uma busca no acervo das teses de doutorado, por entender ser este um caminho importante para discutir/rediscutir o conhecimento já produzido sobre o cuidado. De outro modo, intentou-se tornar visíveis às lacunas na produção do conhecimento e vislumbrar novos horizontes a serem trilhados na pesquisa em enfermagem. Enquanto enfermeiras, militantes no/do cuidado e pesquisadoras, importava-nos, nessa perspectiva, conhecer o que já havia sido produzido, problematizado e experienciado de novo/velho acerca do cuidado. Assim, definiu-se como objetivo do estudo analisar as concepções teóricas de cuidado expressas nas teses de doutorado de um Programa de Pós-Graduação do sul do Brasil.

\section{PERCURSO METODOLÓGICO}

Para alcançar as dimensões e expressões de cuidado produzidas pelo curso de doutorado em Enfermagem de uma universidade brasileira, realizou-se uma busca bibliográfica no acervo das teses do referido programa. A opção por este programa se deu pela diversidade de enfoques, dimensões e linhas de cuidado peculiares ao mesmo. Considerou-se como fator determinante, a qualificação dos profissionais e o especial significado atribuído à vivência e à prática do cuidado seja na relação consigo mesmo, seja na relação com o outro e com a sociedade.

O estudo é do tipo bibliográfico, com abordagem qualitativa dos dados, tendo como objeto de análise as teses de doutorado defendidas no período de 1995 a dezembro de 2005. Este período foi determinado pela primeira e última tese defendida no programa até o início da coleta de dados deste estudo.

Para alcançar o objetivo proposto, o estudo foi desenvolvido em três etapas. A primeira compreendeu a identificação das teses na página eletrônica do programa, totalizando 111 teses defendidas. A 
segunda etapa compreendeu a seleção das teses que apresentaram o cuidado como objeto de investigação a partir da leitura dos resumos. Nesta etapa foram selecionadas 39 teses. Destas, duas (02) não foram localizadas na biblioteca da universidade e três (03) não apresentaram dados consistentes sobre concepções de cuidado nos resumos. Salienta-se, como fator determinante para esse tipo de busca e análise, a objetividade e clareza do resumo de pesquisa, que deve retratar, de forma consistente e abrangente, o objeto de estudo. Pareceu-nos, nessa investigação, que estes aspectos nem sempre foram considerados como relevantes na elaboração dos referidos resumos, o que de alguma forma dificultou a coleta e a seleção das teses. Sendo assim, o material para investigação foi constituído por 34 teses.

$\mathrm{Na}$ terceira etapa, as pesquisadoras realizaram mais uma vez, leitura criteriosa dos resumos e de alguns capítulos da tese entre eles, a introdução, os resultados, as conclusões e as considerações finais. Para a análise dos dados, foram seguidas as fases de ordenação, classificação e análise final, ${ }^{4}$ como imprescindíveis para o processo em questão. Prosseguiu-se com a organização dos dados, que compreendeu a fase de ordenação, classificação e agrupamento dos mesmos a partir do contexto e das concepções de cuidado apresentados nas teses. Nesse processo, a postura das autoras foi a de questionar e problematizar os dados levantados, no sentido de apreender as estruturas relevantes e formar as idéias centrais sobre as concepções de cuidado. A última fase do processo consistiu em discutir, no interior dos temas emergentes, as concepções de cuidado que emergiram ao longo do percurso.

\section{ANÁLISE E DISCUSSÃO DOS RESUL- TADOS}

As teses analisadas possuíram, de modo geral, certa similaridade em relação aos sujeitos da pesquisa. Da totalidade das teses, $32 \%$ centraram a investigação na equipe de enfermagem, seguida por aquelas que abordaram o cuidado na família $(17,6 \%)$, enquanto que $11,7 \%$ utilizaram as produções científicas da enfermagem enquanto fonte de dados. Vale ressaltar, na perspectiva dos sujeitos das pesquisas, que os diferentes ciclos da vida humana foram contemplados, ou seja, as pesquisas envolveram recém-nascidos, crianças, adolescentes e idosos. Essa multiplicidade de sujeitos demonstra, numa visão mais crítica, a ampla inserção do enfermeiro na sociedade, isto é, seu compromisso responsável com as questões sociais nas mais diferentes fases $\mathrm{da}$ vida. $\mathrm{Na}$ quase totalidade das teses (31), as pesquisas foram realizadas diante de uma situação de doença/agravo, tanto no ambiente hospitalar quanto no domicílio, evidenciando concepções de cuidado nas relações de cuidado-doença. Muito embora os contextos para a pesquisa tenham sido variados, enfatiza-se o ambiente hospitalar como o mais prevalente.

\section{Quadro 1 - O cuidado em saúde/doença.}

\begin{tabular}{|l|l|}
\hline Temas & Estruturas relevantes \\
\hline & O cuidado que valoriza o outro. \\
& Cuidado atento e comprometido. \\
& Cuidado impregnado pelo amor. \\
& Cuidado é pensar no outro. \\
& Cuidado como prática social. \\
& Cuidado como produto da responsabilidade com o outro. \\
& Cuidado na coexistência da ciência e da arte. \\
1. Cuidado individualizado & Cuidado que implica valorizar o outro. \\
2. Cuidado amoroso & Cuidado como essência do ser humano. \\
3. Cuidado global & Cuidar como atitude permanente de interesse. \\
4. Cuidado enquanto sistema cultural & Cuidar como "estar presente". \\
& Cuidado que envolve conhecimentos, comportamentos, valores, habilidades \\
e atitudes. & Cuidado envolve fatores sociais, culturais, sociais e psicológicos. \\
& Cuidado é determinado por valores religiosos e morais. \\
Cuidado integra conhecimentos oriundos do saber popular e do saber pro- \\
fissional. \\
Cuidado como resultado de respostas organizadas frente aos agravos de \\
saúde. \\
Cuidado é orientado por quem vive a doença. \\
A pessoa é cuidada naquilo que compreende como necessário. \\
As crenças e práticas populares não se excluem dos cuidados profissionais.
\end{tabular}


A análise permitiu enumerar as seguintes concepções de cuidado: cuidado em saúde/doença; cuidado como processo interativo; cuidado em um sistema de cuidados; cuidado de si; cuidado domiciliar e cuidado familiar. Essas diferentes compreensões demonstram, em síntese, a riqueza do cuidado no processo de viver humano e cuja investigação não apresenta nenhuma hierarquia e/ou linearidade. As concepções de cuidado serão apresentadas em quadros com os respectivos temas e estruturas relevantes. Assim, a primeira a ser apresentada é a concepção - o cuidado em saúde/doença (Quadro 1).

A dimensão do cuidado em saúde/doença é a expressão mais habitual e revolucionadora no contexto da saúde. Nas teses exploradas, ficou evidente a necessidade por uma compreensão mais ampliada do cuidado à luz de novos referenciais. $\mathrm{O}$ cuidado como ser e fazer profissional tem assumido, ao longo da história, diferentes contornos e também vem sendo exercido por várias classes profissionais que não só os da enfermagem.

O cuidado em saúde, compreende pela sua dinamicidade e interatividade, a configuração de um sistema complexo, que supera qualquer dimensão de cuidado linear, fragmentário e/ou unidimensional. Desse modo, afirma-se enquanto um fenômeno relacional que liga/religa, transforma, mantém ou produz acontecimentos, componentes e indivíduos. ${ }^{1} \mathrm{~A}$ atividade de cuidado é feita pela ação/negociação/deliberação de seus cuidadores mediante necessidades levantadas, normalizadas ou não, ou de solicitações diversas. ${ }^{1} \mathrm{O}$ ato de cuidar pode ser aprendido, desaprendido, reaprendido, transmitido e partilhado apesar de ser único, particular e singular, porém em momentos, espaços e movimentos não isolados das situações múltiplas do viver social. O cuidado caracteriza-se também pelas ações da equipe de saúde realizadas com ou para o ser cuidado, visando prevenir, minimizar ou eliminar os seus problemas, buscando concordância com as crenças e valores do outro, em um educar permanente. ${ }^{1}$ Do ponto de vista existencial, o cuidado se acha antes de toda ação e atitude do ser humano, ou seja, ele está presente em toda atitude e situação de fato. No segundo quadro (Quadro 2) apresentamos o cuidado como processo interativo.

\section{Quadro 2 - O cuidado como processo interativo.}

\begin{tabular}{|c|c|}
\hline Temas & Estruturas relevantes \\
\hline $\begin{array}{l}\text { 1. Cuidado terapêutico } \\
\text { 2. Atitude de cuidado } \\
\text { 3. Cuidado compartilhado } \\
\text { 4. Cuidado expressivo } \\
\text { 5. Cuidado objetivo } \\
\text { 6. Cuidado subjetivo }\end{array}$ & $\begin{array}{l}\text { Processo interativo entre o cuidador e o ser cuidado. } \\
\text { Estar com o outro e ser com o outro. } \\
\text { Processo de pessoas iguais em sua essência. } \\
\text { Processo que envolve pessoas e diferentes papéis. } \\
\text { Um compartilhar que qualifica o cuidado. } \\
\text { Dá-se em uma situação de encontro. } \\
\text { Dá-se no encontro com o outro. } \\
\text { Cuidar é projetar-se em direção ao outro e ao mundo. } \\
\text { Estruturado a partir de relações e interações humanas. } \\
\text { Se expressa na relação com o outro. } \\
\text { Cuidado como atitude de envolvimento. } \\
\text { Produto da interação. } \\
\text { Determinado na interação da equipe e fora dela. } \\
\text { É o estar com as pessoas estabelecendo ligações. } \\
\text { Determinado pelas atitudes de acolhimento. } \\
\text { Definido pela capacidade de escuta. } \\
\text { Surge da sensibilidade frente às trocas com o outro. } \\
\text { Depende das interações entre os indivíduos. } \\
\text { É processo de co-responsabilidade. } \\
\text { É empatia e comunicação. } \\
\text { Determinado pela capacidade de compreender o outro em seu mundo. } \\
\text { É aquilo que se descobre a partir das informações recebidas no contexto da pessoa } \\
\text { cuidada. } \\
\text { Deve transcender o trivial e o procedimento técnico. } \\
\text { Implica valorizar credo, sexo, raça, etnia e situação socioeconômica. }\end{array}$ \\
\hline
\end{tabular}


O cuidado na saúde/enfermagem é um processo de interações e associações entre os seres, sendo parte organizadora do sistema de saúde, parte organizadora dos sistemas de cuidados, coorganizando-se junto aos demais sistemas sociais. ${ }^{1} \mathrm{O}$ cuidado, enquanto conhecimento/saber específico vai muito além de um simples ato simbólico e/ou técnica prescritiva. Inserido num contexto formal/ informal, utiliza-se de diferentes modos, expressões e/ou significados para traduzir o que existe de mais humano naquele que é cuidado e naquele que cuida. Por exemplo, o simples evocar o nome de alguém e conhecê-lo pode significar dar-lhe existência, importância, consideração, cuidado. O cuidado interativo não significa uma renúncia de conhecimentos e técnicas mas, de outro modo, envolve uma apreciação original e singular do outro. O cuidar como forma de interação, determina o envolvimento das pessoas de maneira subjetiva, suscitando mudanças em suas crenças, valores e culturas. $\mathrm{O}$ cuidado interativo se estabelece a partir de forças internas, ou seja, pela troca entre o mundo interior e exterior do ser cuidado e do ser cuidador. Dito de outro modo, o cuidado se refere aos atos decorrentes do processo de interação entre as pessoas, uma vez que o mesmo promove uma relação de troca e empatia entre os envolvidos. A seguir apresentamos o cuidado como sistema de cuidados (Quadro 3).

Quadro 3 - Cuidado como sistema de cuidados.

\begin{tabular}{|l|l|}
\hline Temas & Estruturas relevantes \\
\hline & Construído social e culturalmente. \\
& Construído pela interação dos setores profissional, tradicional, popular e familiar. \\
1. Cuidado assistencial & Caracterizado como um compartilhar de conhecimentos e saberes. \\
2. Cuidado técnico & Processo produtor e protetor da vida. \\
3. Cuidado administrativo & Configura-se por atividades assistenciais, administrativas e legais. \\
4. Cuidado relacional & Determinado a partir de políticas sociais. \\
5. Cuidado complexo & Como rede de relações. \\
6. Cuidado como processo produtivo & É ação e movimento. \\
& É marcado pelas vidas e pelas relações. \\
& Determinado pela comunicação entre o sujeito e o meio social. \\
& Determinado pelos vários saberes profissionais. \\
\hline
\end{tabular}

Avanços na pesquisa e nas práticas em saúde vem configurando, crescentemente, o cuidado enquanto um sistema complexo, isto é, enquanto um fenômeno vital e essencial na vida de todos os seres humanos e da natureza. O cuidado enquanto sistema ultrapassa a lógica prioritária do fazer enfermagem e abarca um processo interativo, dinâmico, solidário e criativo. O cuidado é ao mesmo tempo novo/ velho, existencial/relacional, simples/complexo, unidimensional/multidimensional e é construído continuamente pelos seres que cuidam e os serres que são cuidados. Pensar em sistema de cuidados é apontar para a complexidade dos opostos como ordem/desordem, sujeito/objeto, parte/todo desse sistema e, ainda, compreender aspectos como autonomia, individualidade, relações e atitudes profissionais, entre as quais aquelas relativas às práticas do enfermeiro. No próximo quadro (Quadro 4) apresentaremos o cuidado de si.

O cuidado de si, não se trata de uma verdade e/ou exortação qualquer sobre o egoísmo ou ego- centrismo. Trata-se, no entanto, de uma chamada de atenção no sentido de que para oferecer uma presença significativa ao outro, é preciso ter interesse, ter consciência das próprias potencialidades e fragilidades, saber questionar as próprias fontes de prazer e dificuldades, enfim, de que é preciso tomar a própria realidade nas mãos. Para demonstrar interesse ao outro é preciso que eu tenha interesse para comigo mesmo.

O despertar para o autoconhecimento e o cuidar de si é conseqüência do processo de aprender a cuidar. $\mathrm{O}$ autoconhecimento e o saber cuidar de si influenciam, positivamente o cuidado tendo em vista que o relacionamento interpessoal reconhece as forças, fraquezas e potencialidades do mundo interior. ${ }^{5-6} \mathrm{Ao}$ experienciar o autocuidado e o cuidar de si, os cuidadores oportunizam a auto-reflexão, o extravasamento das emoções, a absorção de vivências que se traduzem em conhecimento. Além disso, oportunizam a si mesmo a autopercepção como sujeito, cuja subjetividade e sensibilidade estão postos em ação. 
Quadro 4 - Cuidado de si.

\begin{tabular}{|l|l|}
\hline Temas & Estruturas relevantes \\
\hline & Determinado a partir de jogos de verdade. \\
& Determinado pelas relações de poder. \\
& Permeado por resistências, recusas e incorporações de comportamentos. \\
& Definido como regras de condutas, verdades e prescrições. \\
& Necessita da relação como o outro. \\
Vincula-se à noção de liberdade. & Definido como viver saudável. \\
Cuidado como atitude & Implica um olhar para si próprio. \\
& Implica em conhecer-se. \\
& O sujeito com capacidade para avaliar e fazer escolhas. \\
& Significa envolver-se consigo mesmo. \\
& Condição para cuidar do outro. \\
& Cuidar é ajudar a outra pessoa a cuidar de si. \\
& Cuidar de si não significa sacrifício. \\
& Cuidar de si é tornar-se responsável por sua própria vida. \\
\hline
\end{tabular}

A enfermagem, diferentemente dos demais cuidadores requer, além de uma atitude ética e responsável socialmente, um compromisso legal e profissional com a dignidade da pessoa humana, por estar habilitada técnica e cientificamente para tal função. $O$ enfermeiro demanda um papel preponderante nas múltiplas interfaces do cuidado por ser um dos articuladores dos processos de trabalho interagindo com todos os profissionais da saúde e não raramente coordenando a organização destes nos diferentes espaços. Assim, o cuidado como atitude ética e solidária não significa apenas levar em conta as necessidades elementares e naturais do ser humano, mas também a sua liberdade e dignidade enquanto autor (co)criador da sua história. ${ }^{7-8} \mathrm{O}$ cuidado como atitude ética requer, igualmente, do profissional especial atenção à linguagem do corpo, tendo em vista que o estado de espírito, os gestos, a postura e as intenções que ele transmite serão facilmente decodificados pela pessoa sob o seu cuidado. Requer, sobretudo, criar um espaço de encontro, de troca, de compartilhamento capaz de articular as diferenças e manter a unidade numa espécie de dinâmica participativa. No quadro a seguir, apresentaremos o cuidado domiciliar (Quadro 5).

\section{Quadro 5 - Cuidado domiciliar.}

\begin{tabular}{|l|l|}
\hline Temas & Estruturas relevantes \\
\hline \multirow{3}{*}{ Cuidado no domicílio } & $\begin{array}{l}\text { Como envolvimento com o ser humano. } \\
\text { Cuidado que o profissional realiza no contexto da residência dos sujeitos. } \\
\text { Faz parte do cuidado em saúde. } \\
\text { Caracterizado pelo relacionamento interpessoal com forte caráter humano. } \\
\text { Tem conotação de atenção humanizada. } \\
\text { Representa uma etapa da interação simbólica que a enfermeira vivencia com o cliente, } \\
\text { com os familiares e com a equipe de saúde. }\end{array}$ \\
\hline
\end{tabular}

A política do setor da saúde, principalmente no momento histórico atual, está retornando sua atenção para a família no contexto domiciliar, reconhecendo-o como um importante campo de atuação para os profissionais da saúde. Compreende-se ser esta uma possibilidade de estreitar os vínculos e favorecer a responsabilidade social e política dos profissionais envolvidos com o cuidado em saúde, pois é no "cuidado domiciliar que se encontra a essência do ser humano". 9:240

Nessa perspectiva, o cuidado domiciliar é uma das maneiras pelas quais os profissionais podem cuidar tanto em situações de promoção e prevenção como no apoio e na terapêutica de doenças. A presença de doença, nesse espaço, se constitui, de outro modo, uma ruptura e/ou uma nova possi- 
bilidade de organização/reorganização do grupo familiar. Além das incertezas da sobrecarga física, emocional e financeira, o impacto da doença gera mecanismos de defesa, nem sempre favoráveis. $\mathrm{O}$ papel preponderante do profissional cuidador consiste em envolver as pessoas sob seu cuidado nas decisões e ajudá-las a conduzir e auxiliar no enfrentamento dos conflitos, apoiarem esforços e assegurar uma atitude de confiança e reciprocidade. Além do mais, é no domićlíio que o profissional por meio do compartilhamento, e das trocas visualizam os possíveis riscos, as dificuldades e as facilidades com vistas a identificar respostas e elaborar um plano de cuidados condizente com a realidade familiar e domiciliar. A modalidade de cuidado domiciliar confere, em última análise, uma posição de destaque e autonomia ao profissional por exigir deste, a capacidade de planejamento, encaminhamento, decisão, iniciativa, interatividade entre outras, além de uma inserção social ética e comprometida com o ser humano. No último quadro, apresentaremos o cuidado familiar (Quadro 6).

\section{Quadro 6 - Cuidado familiar.}

\begin{tabular}{|l|l|}
\hline Temas & Estruturas relevantes \\
\hline & Cuidado dispensado pela família/familiares. \\
& Cuidado que possui singularidades. \\
& Envolve o cuidado com as roupas, com a alimentação, com a higiene e com \\
& a educação. \\
& A família como espaço de inclusão e acolhimento. \\
& A família como meio de proteção e segurança. \\
1. Cuidado dos familiares & Determinado pelo compartilhar entre os membros da família. \\
2. Tendo que cuidar & Caracterizado por uma rede de apoio na família e na comunidade. \\
3. Família como matriz cuidadora & Estruturado a partir de relações, de disponibilidade e de apoio dos familiares. \\
& Família como suporte da atenção em saúde. \\
& Ao cuidar a família expressa seu modo de vida. \\
& Família como responsável pelo cuidado de seus membros. \\
& Determinado por valores religiosos e morais. \\
& Compreende os cuidados diretos, o controle dos recursos e a continuidade \\
& dos cuidados. \\
\hline
\end{tabular}

A família é apresentada como unidade de cuidado e é a partir dela, que são delineadas e supridas as necessidades de cuidado e, alcançados os objetivos para o bem-estar de seus membros. Com este reconhecimento cabe aos profissionais "reconhecer a necessidade de ouvi-la em suas dúvidas e de considerar sua opinião". ${ }^{10: 35}$

A família configura-se, por outro lado, como um grupo complexo enriquecido por crenças, valores, atitudes e práticas múltiplas ou, ainda, se constitui numa estrutura complexa por conviver com dificuldades, diferenças, encontros/desencontros. Sob essa perspectiva, a enfermagem, ao atuar na família deve considerar estes vários aspectos tendo em vista um cuidado mais amplo e mais próximo da realidade de cada núcleo familiar. Nesse sentido, a presença do profissional de saúde junto à família possibilita a organização/reorganização/planejamento no que diz respeito à delimitação de metas para minimizar o impacto dos transtornos inerentes ao processo de viver com saúde/doença.
A família é um sistema de saúde, ${ }^{11}$ mas é também uma unidade dinâmica e, como tal, possui um processo de cuidar próprio/singular, onde supervisiona e interage com o estado de saúde de seus membros, toma decisões, acompanha e avalia a saúde e a doença de seus componentes. ${ }^{12}$ No sistema de saúde, a família passa a ser co-participante do cuidar, estabelecendo relações complementares com os diferentes atores e buscando alternativas que viabilizam novos encontros, adaptações, envolvimentos afetivos e responsabilizações. A família, nesse sentido, favorece os vínculos de confiança, sinceridade, respeito, empatia e reciprocidade entre seus membros. $\mathrm{O}$ cuidado mais que um simples ato, passa a ser uma atitude de amor para com a pessoa amada e com quem se preocupa. O processo de cuidar de um familiar favorece, em outras palavras, sentimentos de satisfação e o aumento de confiança.

O cuidar da família como sistema social remete ao cuidado complexo o qual se reveste de diálogo, compreensão, sensibilidade para ouvir atentamente, 
carinho, amor, respeito, conhecimento e habilidade técnica avançada ou saberes específicos sobre a saúde, a doença, a organização do cuidado e dos serviços de saúde, as políticas sociais, dentre outros. ${ }^{13}$

\section{CONSIDERAÇÕES FINAIS}

A partir do levantamento e análise das concepções teóricas de cuidado nas teses investigadas, o cuidado pode/deve ser compreendido como produto e serviço nas suas múltiplas dimensões, relações e interações, isto é, como um sistema de produção de serviços personificado e singular na sua maneira de ser e existir na sociedade. Requer, para isso, um posicionamento diferenciado por parte do enfermeiro que, muitas vezes, atrelado a um modelo reducionista e simplificado, visualiza de modo fragmentado e funcionalista os micro espaços do cuidado.

As concepções de cuidado, em suma, passam necessariamente pelo resgate dos pequenos e/ou grandes eventos e movimentos do dia-a-dia e dos diferentes espaços/contextos e situações em que o ser humano se encontra. Nessa perspectiva, a complexidade do cuidado parece estar cada vez mais evidente nas variadas expressões sociais, profissionais, familiares e individuais. Pelo enfoque sistêmico o cuidado possui a capacidade/habilidade de dialogar com as diferentes dimensões vitais/existenciais e principalmente profissionais, que intentam um viver mais saudável.

\section{REFERÊNCIAS}

1 Erdmann AL. Sistema de cuidados de enfermagem. Pelotas (RS): UFPel/Ed. Universit.; 1996.

2 Waldow VR. Cuidado humano: o resgate necessário. Porto Alegre (RS): Sagra Luzzatto; 1998.
3 Silva MJP, Gimenes OMPU. Eu: o cuidador. Rev. Mundo Saúde. 2000 Jun-Ago; 24 (4): 307-9.

4 Minayo MCS. Desafio do conhecimento. 5a ed. São Paulo (SP): Hucitec-Abrasco; 2000.

5 Moscovici F. Desenvolvimento interpessoal. 5a ed. Rio de Janeiro (RJ): José Olympio; 1996.

6 Watson J. Enfermagem: ciência humana e cuidar uma teoria de enfermagem. Rio de Janeiro (RJ): Lusociência; 2002.

7 Bettinelli LA. Demonstrando consciência solidária nas relações do cuidado hospitalar: fazendo emergir o sentido da vida [tese]. Florianópolis (SC): UFSC/ Programa de Pós-Graduação em Enfermagem; 2001.

8 Petit C. Cuidar neste mundo: uma exigência da humanidade. In: Hesbeen W. Cuidar neste mundo. Paris (FR): Lusociência; 2004. p.87-102.

9 Lacerda MR, Olinisk SR. O familiar cuidador e a enfermeira: desenvolvendo interações no contexto domiciliar. Acta Scientiarum. Health Sciences 2004 Nov-Dez; 26 (1): 239-48.

10 Victor JF, Moreira TMM. Integrando a família no cuidado de seus bebês: ensinando a aplicação da massagem Shantala. Acta Scientiarum Health Sciences. 2004 Nov-Dez; 26 (1): 35-9.

11 Elsen I. Cuidado familial: uma proposta inicial de sistematização conceitual. In: Elsen I; Marcon SS, Silva RS. O viver em família e sua interface com a saúde e a doença. Maringá (PR): UEM; 2002. p.11-24.

12 Resta DG, Budó MLD. A cultura e as formas de cuidar em família na visão de pacientes e cuidadores familiares. Acta Scientiarum. Health Sciences. 2004 Nov-Dez; 26 (1): 53-60.

13 Erdmann AL, Marino SRA, Mello ALSF, Meirelles BHS. Gestão das práticas de saúde na perspectiva do cuidado complexo. Texto Contexto Enferm. 2006 Jul-Set; 15 (3): 483-91. 